\title{
POLÍTICA SOCIAL Y SALUD: DETERIORO DEL TRABAJO INFORMAL POR LA COVID-19, EL CASO DE TAXISTAS EN MÉXICO
}

\author{
SOCIAL POLICY AND HEALTH: DETERIORATION OF INFORMAL WORK DUE \\ TO COVID-19, THE CASE OF TAXI DRIVERS IN MEXICO
}

\author{
Abigail Martínez-Mendoza ${ }^{1}$ * iD; Giselle Martínez-Ortíz ${ }^{2}$ (D). \\ 1. Universidad Autónoma Metropolitana, México. a.martinez@correo.ler.uam.mx \\ 2. Universidad Autónoma Metropolitana, México.2173073402@correo.ler.uam.mx \\ *Autor de correspondencia: Abigail Martínez-Mendoza, email: a.martinez@correo.ler.uam.mx
}

\section{RESUMEN}

El objetivo de este trabajo es describir las afectaciones que ha provocado la pandemia por la COVID-19 en los trabajadores informales, como los conductores de taxis, en la segunda entidad mexicana con más contagios; y señalar las políticas públicas dirigidas a este sector. Se trata de un trabajo con enfoque cualitativo, que emplea las técnicas de investigación documental, la entrevista semiestructurada y la observación en campo. Los resultados muestran una reducción de ingresos del $50 \%$, afectaciones emocionales negativas, y la ausencia de políticas dirigidas a este sector durante esta crisis sanitaria. Se concluye la necesidad de redefinir las características del llamado trabajo informal, dado que no todos los trabajadores de este sector están plenamente fuera del marco legal.

Palabras clave: pandemia; COVID-19; políticas sociales; taxistas; trabajo informal.

Cómo citar:

Martínez-Mendoza, Abigail; Martínez-Ortíz, Giselle. (2021). Política social y salud: deterioro del trabajo informal por la COVID-19, el caso de taxistas en México. Revista de Investigaciones Universidad del Quindio, 33(2), 201-213. https://doi. org/10.33975/riuq.vol33n2.800 


\begin{abstract}
The objective of this work is to describe the effects of the COVID-19 pandemic on informal workers, such as taxi drivers, in the second Mexican entity with the most infections; and indicate the public policies directed to this sector. It is a work with a qualitative approach, which uses the techniques of documentary research, the semistructured interview and observation in the field. The results show a 50\% reduction in income, negative emotional effects, and the absence of policies directed at this sector during this health crisis. The need to redefine the characteristics of so-called informal work is concluded, since not all workers in this sector are completely outside the legal framework.
\end{abstract}

Keywords: pandemic; COVID-19; social policies; taxi drivers; informal work.

\section{INTRODUCCIÓN}

Este trabajo se enfoca en conocer las afectaciones que ha provocado la pandemia en los conductores informales de transporte colectivo concesionado, particularmente en la segunda entidad mexicana con mayor número de contagios por COVID-19. Profundizar en el análisis sobre el tema, puede contribuir a proponer o elaborar políticas eficientes dirigidas al sector informal o en este caso, que beneficien a los trabajadores que se desempeñan como taxistas colectivos.

Los trabajadores que se desempeñan en el sector informal son los más afectados por la pandemia, porque son quienes acumulan más pérdidas de empleo e ingresos (Aguilar, 2020). En el empleo informal se considera a todos aquellos trabajadores por cuenta propia, empleadores, miembros de cooperativas de productores, trabajadores familiares, auxiliares y asalariados, que no están sujetos a la legislación laboral nacional, el impuesto sobre la renta, la protección social o determinadas prestaciones relacionadas con el empleo (OIT, 2003). De acuerdo con la OCDE (2020) el empleo informal es decisivo para la supervivencia de los trabajadores excluidos del sector formal, ya que suele ser la única manera en que quienes con pocas cualificaciones escapen de la pobreza.

En México, de acuerdo con el Instituto Nacional de Estadística y Geografía (INEGI), en el primer trimestre de 2021, el 55.1\% de la Población Económicamente Activa (PEA) se desempeña en el empleo informal (INEGI, 2021a), es decir, económicamente hablando México se sostiene por los trabajadores informales; entre los cuales destacan, por mencionar algunos, los comerciantes ambulantes, trabajadoras domésticas, pequeños comerciantes, trabajadores autónomos y taxistas. Este sector informal aporta una cuarta parte del PIB, el 23\% (SEGOB, 2019).

La segunda entidad con más aportaciones al PIB nacional es el Estado de México con $8.8 \%$ para el 2021, particularmente, en el segundo trimestre del mismo año, el 56.5\% de la PEA corresponde al sector informal (INEGI, 2021b). Nuevamente, se observa que la economía, de esta entidad, se apuntala sobre el sector de los trabajadores informales.

Todo lo anterior a pesar del actual brote de coronavirus; para el caso mexicano, en parte debido a las medidas de confinamiento implementadas para contrarrestar la propagación del virus que implican el paro de aquello denominado como actividades no esenciales (DOF, 2020a). Por lo que la suspensión de labores para la mayoría de los trabajadores informales no es una opción, ya que muchos de estos trabajos son de subsistencia familiar; adicionalmente la mayoría no cuenta con protección social. 


\section{El trabajo informal durante la pandemia}

En México, el 28 de febrero de 2020 se anunció oficialmente el primer caso de coronavirus, y el primer fallecimiento se presentó el 18 de marzo (Secretaría de Salud, 2020), y cinco días después fue decretado el confinamiento generalizado (DOF, 2020b).

Respecto al empleo informal, ante el confinamiento, los datos revelan una disminución. Según el INEGI, en México en 2019 y a principios de 2020 , la tasa de informalidad laboral era de aproximadamente $56 \%$ de la PEA, lo que equivale a 31,3 millones de personas que están fuera de la legislación laboral.

Por otra parte, y con base en el informe de la Organización Internacional del Trabajo (OIT) coordinado por Feix (2020), sobre el panorama laboral en México, se refiere que entre los meses de marzo y abril de 2020 la tasa de informalidad se redujo 8 puntos porcentuales, pasando del $55,7 \%$ al $47,7 \%$. Sin embargo, a un mes del confinamiento, en abril, el mismo INEGI, estimó que abandonaron los empleos formales e informales más de 12 millones de trabajadores, de este abandono masivo, más del $90 \%$ provenía de la economía informal (INEGI, ETOE, 2020).

En este sentido, el mismo informe coordinado por Feix (2020) señala que, entre abril y mayo, se vio una recuperación del empleo informal aproximadamente de 1,9 millones, es decir, fue de 20,7 millones a 22,6 millones, lo que trajo consigo un incremento de $4,1 \%$ de la tasa de informalidad, llegando al mes de mayo con $51,8 \%$. Entre junio, julio y agosto, se confirma el ascenso de la tasa de informalidad que alcanzó un $55,1 \%$ de los ocupados. Se puede entender que tras la pérdida o abandono del trabajo sigue siendo una alternativa viable para la subsistencia pese a la ausencia de determinados beneficios sociales.

Ya para octubre y noviembre del mismo año se alcanzó un 56.3\%, sin embargo, en el mes de diciembre volvió a tener una ligera disminución pasando a $55.8 \%$ y a $55.6 \%$ en enero de 2021 . Es decir, el empleo informal ha tenido una variación vinculada a las acciones de gobierno que indican el cierre y apertura de espacios públicos, escenarios principales del empleo informal (Ovando y Salgado, 2021); dicha dinámica de apertura y cierre de determinadas actividades responde al llamado Semáforo de Riesgo Epidemiológico para transitar hacia una nueva normalidad (DOF, 2020c).

Con todo, es interesante notar cómo el sector informal se recuperó desde el mes de mayo de 2020 hasta alcanzar niveles similares antes de la pandemia; de acuerdo con Candelas (2020), la razón de las personas para continuar desarrollando sus actividades de manera normal se encuentra en la urgencia de buscar cotidianamente los medios para sobrevivir, para ellos y sus familias. Muchas de las personas insertadas en la informalidad sobreviven por debajo de la línea de pobreza y al enfrentarse a una crisis como la pandemia quedan expuestos a riesgos de salud y económicos que no pueden ser solventados oportunamente por carecer de protección social y de un ingreso fijo, sumando la debilidad en que se encuentra el sistema de salud, antes y como resultado de la pandemia.

\section{MARCO CONCEPTUAL}

\section{Informalidad laboral y políticas sociales}

De las responsabilidades del Estado para con la sociedad está la distribución de la riqueza y el devenir del bienestar; esto sin duda es parte de la política de gobierno. Especialmente, lo que respecta al empleo y la protección social, versus el desempleo o el trabajo informal.

El uso del término informal como un sector del ámbito laboral comenzó en los años setenta. En 1972, en el informe sobre Kenia, la OIT indicó que los trabajadores pobres logran sobrevivir con actividades marginales a pequeña escala, y que, sin ser delictivas, se encontraban al margen 
de la legislación. Se trata de actividades de sobrevivencia, sin reconocimiento, registro, protección, ni reglamentos, y pese a ello, resultan funcionales para la economía (Infante y Martínez, 2019). Para el caso de América latina y el Caribe, el término fue impulsado por el Programa Regional de Empleo de América Latina y el Caribe (PREALC), de la misma OIT en 1976: "todos los trabajadores y/o empresas en actividades no organizadas, que usan procedimientos tecnológicos sencillos y trabajan en mercados competitivos o en la base de estructuras económicas" pueden comprenderse como el sector informal del empleo (PREALC, 1976: 38).

Brevemente, y más allá de las caracterizaciones que ofrecen los organismos internacionales, se observa que para algunos autores hay énfasis en algunos elementos como la normatividad, la recaudación fiscal, o bien, las pocas ofertas laborales formales. Para De Soto (1986), el concepto de informalidad se basa en la recaudación fiscal y la regulación tributaria como referencias de estudio, donde la informalidad es causada por el exceso de reglamentación pública que obliga a las y los trabajadores a operar en la ilegalidad, ya que no consiguen cumplir con dicha normatividad. En esta misma tesitura, Diaz (2012:41) señala que las actividades informales se llevan a cabo al margen de la legislación fiscal con el objetivo de aumentar los beneficios o por la imposibilidad de cubrir costos de regulación. Como se observa, los enfoques de Díaz (2012) y De Soto (1986) consideran al sector de trabajadores informales como microempresarios.

Por otra parte, Tokman (1987) indica que la informalidad es el resultado de un excedente de oferta de mano de obra con la necesidad de percibir un ingreso para subsistir. De manera similar, Cota y Navarro (2016) mencionan que el sector informal está constituido por todos aquellos trabajadores que no operan bajo relaciones contractuales oficiales, sean por cuenta propia o bajo algún tipo de patrón, ni reciben una cobertura completa por las garantías de leyes mexicanas, así como un sueldo inferior al mínimo establecido, y cuyo servicio tiene una participación en la economía nacional.

En México, y de acuerdo con Robles (2016) la informalidad puede ser definida principalmente bajo dos enfoques. Primero, a nivel agregado, toda empresa menor a 15 individuos, y que carezca de registros contables; es decir, unidades productivas que no pagan impuestos. El segundo enfoque, es a nivel individual y definido como la carencia de cobertura de seguridad social, puesto que, aunque el individuo trabaje en una empresa considerada formal, si no recibe seguridad social, es considerado informal

Asimismo, el INEGI (2014:10) señala que todo el espectro de modalidades ocupacionales, dependientes o independientes, que impliquen "actividades económicas realizadas por los individuos que, por el contexto en el que lo hacen, no pueden invocar a su favor el marco legal o institucional que corresponda a su inserción económica" será considerado trabajo informal. Por lo anterior es posible señalar que México adopta una definición con enfoque legal sobre la informalidad, como lo menciona De Soto (1986), actividades que utilizan medios ilegales para obtener fines legales.

Derivado de lo anterior, y para este trabajo, se retoma lo que desarrolló Martínez (2021:31) al respecto, el trabajo informal considera a "Toda aquella persona que realice actividades laborales que se llevan a cabo al margen de la estricta regulación y legalidad laboral, y por ende no cuente con protección social, prestaciones laborales, jubilación y pensión"; esto es una actividad cuyo objetivo es subsistir debido a que se enfrentan a condiciones de vulnerabilidad, o bien, el objetivo es el crecimiento económico o el emprendimiento, a esto, es pertinente señalar que en México, el 43.9\% de la población vive en pobreza (CONEVAL, 2020).

Atodo lo anterior, se debe sumarlorelacionadocon las políticas sociales en México, invariablemente 
vinculadas por su propia naturaleza al desarrollo y bienestar de la sociedad, y que se asocian con la protección social, prestaciones laborales, jubilación, pensiones y otros elementos. De acuerdo con Martínez y Morales (2021), en México, se pueden observar cuatro momentos de las políticas sociales, a saber:

1. 1970 a 1982, los principales programas sociales estaban dirigidos a grupos marginados: "moldear y dar cauce institucional a las demandas de grupos (...) al margen de las (...) estructuras corporativas" (Barajas, 2002: 555).

2. 1982 a 1994, la atención operó a partir de las demandas de grupos organizados como sindicatos o corporaciones como base social, y con ello "sentar las bases del nuevo modelo de desarrollo: el neoliberal" (Barajas, 2002: 564).

3. 1995 a 2018, la política social se especializó en el uso de minuciosos procesos de focalización, esquemas: "de acuerdo con la lógica de mercado y la exigencia de eficiencia técnica en la atención de la pobreza" (Barajas, 2002: 556).

4. Actualmente, es posible observar que la relación entre el gobierno y las personas fue a partir de que estas conforman una masa potencialmente conflictiva por su marginalidad histórica; pero una forma de contener a dicha masa requería esquemas de transferencias monetarias o en especie y sin intermediarios, pero al mismo tiempo, tal masa debía servir como una nueva base social para los proyectos de gobierno (Martínes y Morales, 2021).

A lo anterior, es pertinente mencionar que la política social se caracteriza por responder a un contexto determinado, por una decisión política realizada jurídicamente con un estatuto científico concreto, e institucionalizada pluralmente, como bien lo señalan Fernández y Caravaca (2011). Si en materia social, los cursos de acción entendidos como políticas públicas (Aguilar, 1992), están destinados a mejorar las condiciones de los grupos sociales más vulnerables o en situación de marginación y pobreza, pero "más que la oferta de servicios de educación, salud, vivienda o alimentación, contemplan también una distribución más equilibrada con miras a reducir las desigualdades" entonces, "las políticas sociales no son el tandeo de la asistencia social, por el contrario, conforman un corpus de acciones centradas en los ciudadanos (Martínez y Morales, 2021:153), como bien señalan estos autores, esto puede ser en una postura romántica, el estricto e inflexible deber ser. Por ello, es necesario considerar las opciones de políticas públicas que implican elegir entre valores en competencia: salud, bienestar, seguridad, paz, justicia, igualdad, libertad, etcétera, esto es, un determinado curso de acción viable para el problema inicial y el contexto prevaleciente (Lara y De la Rosa, 2017).

En este sentido, las políticas sociales en materia de empleo en México implican traer a los trabajadores del mercado laboral informal a la luz de la formalidad. Como lo señala Levi (2010), es fundamental entender las características del empleo para lograr articular una política social más robusta, y a decir, de Pérez (2021), el trabajo formal cuenta con un conjunto de prestaciones sociales provistas por el empleador y garantizadas por el Estado. Así, las acciones enfocadas a la luz del empleo y bienestar también son parte de las políticas sociales (Midgley, 2009).

Particularmente, en México prevalecen desafíos por las características del régimen que se ha fraguado históricamente y que no se han podido revertir (Pérez, 2021), tales como exclusión de amplios sectores, segmentación de la política social que tiende a conservar la diferencia entre derechos y subsidios sociales, concentración del ingreso y precarización del empleo, como es el caso de los conductores de transporte público colectivo, y en especial, los taxistas.

En ese sentido y frente a la pandemia, a través del CONEVAL (2021) se identificaron 667 intervenciones gubernamentales que se relacionan 
con la atención a la emergencia sanitaria, de marzo a agosto de 2020. Algunos de los programas relacionados con el empleo e ingreso son: Programa de Apoyo para el Bienestar de las Niñas y Niños, Hijos de Madres Trabajadoras, Programa de Apoyo Financiero a Microempresas Familiares, Jóvenes Construyendo el Futuro y Programa de Microcréditos para el Bienestar (CONEVAL, 2021).

Sin embargo, las políticas o acciones en beneficio de los trabajadores informales son escasas, lo cual es alarmante ya que muchos de estos trabajadores no tienen o tienen acceso limitado a servicios de salud y dadas las características de su trabajo, están más expuestos al contagio de la COVID-19. Algunas acciones que ha realizado el gobierno mexicano en apoyo a los trabajadores informales es la entrega de "créditos solidarios a la palabra" de 25 mil pesos a 281,000 taxistas, meseros, camaristas y comerciantes de tianguis, como apoyo ante la emergencia sanitaria (SE, 2020).

Además el Gobierno publicó en el mes de junio de 2020 el Programa Sectorial de Trabajo y Previsión Social 2020-2024 de la Secretaría del Trabajo y Previsión Social, que es un programa derivado del Plan Nacional de Desarrollo 20192024 (PND), el cual uno de sus objetivos es "lograr la inserción en un empleo formal de las personas desempleadas, trabajadores en condiciones críticas de ocupación y personas inactivas con disponibilidad para trabajar, con atención preferencial a quienes enfrentan barreras de acceso a un empleo formal" (DOF, 2020d: 1).

Por su parte, el Estado de México, que sólo por detrás de la Ciudad de México, ha sido la segunda entidad federativa con más casos asociados al coronavirus desde el inicio de la pandemia; llegando al mes de noviembre de 2021, con 983,776 casos en la capital del país, y 378,745 en el Estado de México (SEGOB, CONACYT, 2021).
En esta entidad, en julio de 2020 se emitió el Acuerdo de la Secretaría del Trabajo del Estado de México, por el que se expiden las reglas de operación del Programa de Desarrollo Social "Programa de Apoyo al Desempleo", el cual va dirigido a personas de 18 años en adelante que vivan en la entidad y que hayan perdido su empleo ya sea formal o informal, a causa de la pandemia de la COVID-19 (Gaceta del Gobierno, 2020a).

Mientras que para el 2021, el Gobierno Federal a través de la Secretaría del Trabajo y Previsión Social emitió el "Acuerdo mediante el cual se establecen las Reglas de Operación del Programa de Apoyo al Empleo". Este programa tiene como objetivo lograr la inserción en un empleo formal de desempleados y trabajadores en condiciones críticas de ocupación, con atención preferencial a quienes enfrentan barreras de acceso al empleo formal (DOF, 2021).

Dicho lo anterior, es posible señalar que el Gobierno Mexicano ha generado muy pocas políticas públicas y/o programas dirigidos al sector informal, y los cuales sólo van orientados a la formalización. De acuerdo con Rivera, et al (2016) México tiene una posición muy apegada a las teorías ortodoxas, en la que la informalidad constituye un ancla para el desarrollo y las políticas constituyen un esfuerzo para la formalización, y si es el caso, prevalece la escasez de planes y programas dirigidos al sector informal.

\section{Empleo informal y taxistas}

En México, el transporte en la modalidad de taxi constituye un servicio público que puede ser prestado indirectamente a través de una concesión del Estado, el cual es encargado de supervisar y controlar la prestación de dicho servicio en lo que refiere a número de vehículos, áreas de operación, tarifas, bases, entre otros (Hernández y Galindo, 2016, 2020).

Cabe mencionar, que la modalidad de taxi concentra el mayor número de concesionarios 
individuales, además representa la mayorcantidad de vehículos registrados de servicio público, y se agrupan en asociaciones civiles o corporativos. En el cuarto trimestre de 2020, las personas que trabajan como conductores de autobuses, camiones, camionetas, taxis y automóviles de pasajeros fueron 1,180,000 personas en México, y en la entidad del Estado de México, para el mismo periodo, 228 mil (DataMexico, 2020), se trata de una de las entidades federativas con mayor número de conductores concesionados.

Emplearse como conductor de taxi representa una posibilidad de crecimiento económico; otros recurren a ello frente a la necesidad de subsistir mientras esperan integrarse a un trabajo formal como lo menciona Tokman (1985), y a su vez como último recurso antes de quedar desempleado. Otra razón para ser taxista es porque prefieren evitar pagar algunos impuestos, tal como ya lo indicó De Soto (1986), dichos impuestos pueden ser el seguro contra accidentes, tenencia, verificación, licencias para conducir, concesiones, por señalar algunos; en suma, pagan para poder trabajar (Martínez, 2021).

Tabla 1. Tributaciones del transporte en modalidad de taxi

$$
\begin{array}{cc}
\text { Requisitos } & \text { Costo } \\
\text { (Pesos mexicanos) }
\end{array}
$$

\begin{tabular}{ll}
\hline $\begin{array}{l}\text { Inscripción al Registro de } \\
\text { Transporte Público }\end{array}$ & $\mathrm{S} / \mathrm{C}$ \\
\hline Prórroga de concesión & $\$ 1,564.00$ \\
\hline Baja de vehículo & $\$ 537.00$ \\
\hline $\begin{array}{l}\text { Cambio o sustitución de } \\
\text { vehículo. }\end{array}$ & $\$ 705.00$ \\
\hline Cambio de propietario & $\$ 266.00$ \\
\hline
\end{tabular}

Reposición de tarjetas de circulación y/o título de $\$ 1,248.00$ concesión

Modificación de
$\begin{aligned} & \text { Beneficiarios del título de } \$ 1,619.00 \\ & \text { concesión }\end{aligned}$

Seguro de responsabilidad o seguro interno de viajero

Licencia vigencia 1 año $\$ 993.00$

\begin{tabular}{|c|c|}
\hline $\begin{array}{l}\text { Autorización de la } \\
\text { Cromática y su Diseño }\end{array}$ & $\$ 1,053$ \\
\hline Tenencia y Refrendo & $\$ 1,500$ aprox \\
\hline Verificación & $\$ 300-\$ 900$ \\
\hline
\end{tabular}

De lo anterior se puede señalar que los taxistas no son del todo trabajadores informales, pagan para trabajar.

Por otra parte, de acuerdo con Hernández y Galindo (2020), en su gran mayoría los conductores de taxi tienen un rango de edad desde los 18 a los 79 años; para los más jóvenes esta actividad constituye su primer empleo, mientras que para las personas mayores ven en este trabajo un complemento a su jubilación o esta es su única fuente de ingresos.

La figura del taxista, mujer $\mathrm{u}$ hombre suele ser la de un trabajador o trabajadora independiente, propietario o no del vehículo y de la licencia, sin un ingreso fijo que dependerá de las tarifas, afluencia de pasajeros, los costos de mantenimiento de la unidad y el pago de la renta del automóvil, en caso de no poseer la propiedad. En consecuencia, sus ganancias suelen ser variables, además de tener jornadas extensas (Ledesma et al, 2012). De esta forma, es común que no cuenten con protección social, prestaciones laborales, jubilación y pensión, o bien, representación sindical, dado que prevalece la ausencia contractual entre patrón y trabajador (Pogliaghi, 2012).

En este sentido, las labores del taxista pueden considerarse por cuenta o iniciativa propia, o bien, como trabajo independiente o autónomo, dado que quien lo realiza tiene el control sobre el proceso de trabajo y no existe subordinación (Martínez, 2021). No obstante, aunque no existe una relación contractual como tal, sí existen formas de organización del trabajo, ya que las asociaciones y empresas que agrupan a estos taxistas establecen pautas para la prestación del servicio: "hay situaciones en las que las personas 
pueden trabajar por cuenta propia, pero el modo en que trabajan está controlado de cerca por otra organización o empresa matriz" (OIT, 2018:3). Esto incluye a muchos taxistas, repartidores, consultores de venta directa, y otras formas de trabajo denominado informal.

Del mismo modo, al taxista-taxi se le puede considerar empresa del sector informal, ya que en el término empresa se incluyen tanto las unidades automovilísticas que contratan a trabajadores como a unidades administradas por particulares que trabajan por cuenta propia o son trabajadores independientes, ya sea solos o con la ayuda no remunerada de familiares. Incluye a los trabajadores en cualquier situación laboral si se considera que participan en una empresa informal (OIT, 2013). Por tanto, los vendedores ambulantes, los taxistas y los trabajadores domésticos autónomos según la OIT se pueden considerar empresas.

Con todo lo anterior, se podría concluir que los conductores de taxi tienen un empleo informal por cuenta propia; o bien algunos que trabajan en sus propias empresas del sector informal, y su trabajo involucra una complejidad de situaciones laborales.

De este modo, la figura de los taxistas está en la frontera laboral de lo informal versus la formalidad, resaltando la subsistencia debido a la ausencia de protección social, que el Estado debe brindar.

Ante la crisis de la pandemia por la COVID-19 y con las medidas de confinamiento implementadas por el gobierno, ocasionó un impactó en las actividades de los conductores de taxi, porque los espacios públicos son la fuente de sus ingresos, diversas actividades económicas no esenciales pararon, otras tantas se continuaron realizando desde casa, y sin duda esto significó una disminución de la demanda del servicio y la reducción de ingreso. En el caso de los taxistas, continuaron sus actividades laborales porque se consideran una actividad esencial: de los sectores fundamentales de la economía como financieros, el de recaudación tributaria, industria de alimentos y bebidas, servicios de transporte de pasajeros y de carga, entre otros (DOF, 2020a), esto de acuerdo con las acciones extraordinarias para atender la emergencia sanitaria en México.

En general, se observa una contradicción, pues, mientras quienes trabajan por formar parte de las actividades esenciales, otros, no trabajan o redujeron su movilidad y carga laboral; haciendo de esto, un círculo vicioso, afectando a los trabajadores independientes. Y pese a que continuaron, el trabajo de taxista también es vulnerable al contagio debido a una constante exposición a otras personas; adicionalmente están los gastos para la prevención de riesgos, como es el uso de cubrebocas, gel antibacterial, colocación de barreras físicas, limpieza y desinfección constante.

Respecto a las medidas sanitarias que involucran al transporte público se promulgaron regulaciones sobre movilidad que implican acciones y afectaciones al trabajador del taxi. Las acciones para reducir la movilidad en las calles de la entidad y fortalecer las medidas con relación a la estrategia de Fase 3 por COVID-19, se implementa el programa provisional Hoy No Circula extendido, en el cual se da a conocer los vehículos que pueden circular sin restricción alguna (DGPCCA, 2020). Para el Estado de México, a través de la Gaceta del Gobierno (2020b), se publicó el acuerdo donde se determinan las acciones que deberán llevar a cabo los trabajadores con motivo del virus SARS-Cov2; ahí se indica el uso de señalamientos sobre la COVID-19, uso de cubrebocas y gel antibacterial, sanitización de la unidad; y además de restringir la cantidad de pasajeros que podían transportar, para los taxistas se determinó deberían de transportar solo a tres pasajeros, de los cuales, dos en el asiento trasero, y uno en frente. En total, cuatro personas a bordo del automóvil, esto cuando en México, los taxis colectivos llevan normalmente hasta seis personas a bordo. 


\section{METODOLOGÍA}

Es una investigación de enfoque cualitativo, de tipo documental y de campo, haciendo uso de la técnica de la observación participante y la entrevista semiestructurada. Debido a las condiciones apremiantes de salud, el trabajo in situ se realizó en el municipio de Lerma, Estado de México, especialmente en la ruta más larga, que va de Xonacatlán-Puente San Mateo, y viceversa. La ruta recorre una distancia de $46 \mathrm{~km}$, aproximadamente, y tiene una gran afluencia de usuarios ya que se brinda servicio a la población de 3 regiones, del municipio.

Se consultaron y revisaron fuentes académicas, notas periodísticas, e informes de la OIT, PREALC, OCDE, INEGI, entre otros. En este sentido, se utilizó la investigación documental para la revisión de tres elementos teóricos: COVID-19; sector informal, especialmente conductores de taxi y políticas sociales, como los que ya fueron expuestos.

Igualmente, en el trabajo de campo se emplearon entrevistas semiestructuradas con el objetivo de conocer la opinión de los conductores de taxi acerca de las afectaciones que ha causado la COVID-19, en su vida laboral y personal, con el propósito de registrar las situaciones en las que trabajan.

Se entrevistó a los conductores de taxis, de manera aleatoria, siguiendo las medidas y protocolos de seguridad sanitaria para la protección contra la COVID-19. Se arribó a los sitios de aparcamiento: Xonacatlán o Puente San Mateo; las autoras abordaron el servicio como cualquier pasajero y al interior de la unidad se entablo la entrevista, a modo de conversación, que retomó las preguntas previamente diseñadas. El número de entrevistas obtenidas fueron 6 , las cuales duraron entre 45 y 50 minutos, el tiempo que dura el recorrido.

\section{RESULTADOS Y DISCUSIÓN}

Si bien los resultados están lejos de ser generalizables, sí ofrecen un panorama del impacto socioeconómico en los trabajadores informales. Principalmente se destaca que existen dos vías por las cuales el trabajo informal como taxista es viable; primero, por las condiciones de vulnerabilidad y subsistencia, y de la segunda observación, una oportunidad de crecimiento económico o un proyecto de emprendimiento en el trabajo como taxista. En este sentido se observa que, en efecto, como ya lo mencionó Martínez (2021), De Soto (1986), Díaz (2012) y Tokman (1987), los conductores de taxi no cuentan con los beneficios del bienestar social, derivados del trabajo formal; sin embargo, realizan diferentes pagos que implican un impuesto (Martínez, 2021), quizá esto sea insuficiente para cubrir los gastos de la incorporación a los servicios de bienestar. Esto es una clara ambigüedad en la denominación de este y otros trabajos en la misma circunstancia, que, en todo caso, pueden nombrarse semi-informal.

Otros resultados relevantes, son con respecto al grado de escolaridad de los conductores de taxi, alcanzando apenas los nueve años de estudios básicos. Frente a este dato se puede observar la relación estrecha entre escolaridad e informalidad, de acuerdo con el INEGI (2020c) el $67.6 \%$ de la población con bajos niveles de escolaridad están incorporados al sector informal.

En cuanto a las jornadas de trabajo, los conductores señalaron que estas son entre $10 \mathrm{y}$ 16 horas diarias, debido a que ha sido necesario compensar las ganancias; en algunos casos, hubo quien se vió obligado a disminuir la jornada laboral debido a la baja demanda del transporte.

Adicionalmente, ya sea con jornadas extendidas o disminuidas, se laboran todos los días de la semana. Cabe señalar que, en México, la Ley Federal del Trabajo, señala que las jornadas laborales son de 8 horas diarias, y entre cinco y seis días a la semana. 
Por otra parte, los entrevistados señalan que, durante el confinamiento, su economía se vio muy afectada, alrededor del 50\% en sus ingresos, debido a que los niños no iban a la escuela y los trabajadores laboraban en su casa.

“...(antes de la pandemia) desde las cinco de la mañana a estas horas que van a hacer las 10 (de la mañana) ya traíamos $700-800$ pesos, y ahorita pues nada más traigo como 400. Cuando estuvo dura la pandemia había veces que llevaba a la casa $80-70$ pesos y uno cuando está bien se llevan hasta 300-400 pesos"

"Antes sacaba un aproximado como de 600 diarios, ahora a veces saco 300, 200; bueno es imprescindible no hay cuota fija, y a parte la gasolina, lo que hago en bruto serían como 600700 pesos, pero tengo que apartar para la gasolina, para mí y también para los gastos de la unidad, como que ya no es redituable"

En cuanto a las relaciones familiares algunos entrevistados refieren que, debido a la reducción de sus ingresos, los proyectos familiares como la construcción de vivienda y las relaciones de pareja se vieron afectadas.

"(antes de la pandemia) yo trabajaba en empresarial y cuando bajo la chamba porque ya no teníamos ni de dónde sacar de fábricas, me descansaron. En ese tiempo era cuando estaba con la que era mi esposa, logré guardar casi como $\$ 10,000$ (pesos mexicanos) que era para hacer yo según mis cuartos... dije pues en lo que consigo (trabajo) yo le dije a la que era mi señora pues agarra de lo que ya guardamos, el dinero me alcanzó para un mes, en un mes yo no podía conseguir trabajo, cuando logré conseguir trabajo fue en el taxi”

"sí ya llevo 8 meses separado, (¿y por qué se separaron? ¿fue porque no les alcanza el dinero? ).. pues tantito eso y tantito qué la acostumbre a lo bueno y cuando vió que ya no hubo, pues dice de dónde no, este no me va a sacar ni a pasear ahora (con pocos ingresos en pandemia)"

Y aunque en estas entrevistas no se coincidió con alguien que se haya enfermado de COVID-19, todos los entrevistados manifestaron que sí conocen a compañeros taxistas que se contagiaron de esta enfermedad: "Sí, hubo uno que se encamó casi como un mes y medio, pero no pisó el hospital". "Pero los compañeros sí se han enfermado, les ha pegado a varios". En efecto, como ya se indicó, el no tener acceso a los servicios de salud hace de este sector de trabajo, una fuente de población vulnerable a contraer el virus y con ello ver mermadas todas sus actividades.

También mencionan que existe el miedo de ser contagiados en su área de trabajo y transmitir el virus a su familia, refieren sentirse frustrados y tristes. Si bien el brote de la COVID-19 resulta estresante para la mayoría de las personas, Hernández (2020) refiere que, en situaciones de precariedad laboral y por tanto económica, prevalece una condición de vulnerabilidad por el estrés que ello provoca, a su vez, esto representa un factor de riesgo para la salud emocional.

Al indagar sobre las acciones del gobierno en beneficio de los trabajadores informales, indicaron que no hay acciones dirigidas a ellos, por consiguiente, tampoco se han beneficiado de algún programa u apoyo, ni ahora ni antes. Esta información muestra que a nivel municipal no se han implementado acciones o políticas centradas en el sector informal y mucho menos a los conductores de taxi; lo mismo pasa a nivel federal, las políticas son escasas, como ya se mencionó.

En síntesis, los resultados refieren que: 1) a nivel económico los conductores de taxis han visto una disminución del $50 \%$ en sus ingresos; 2) en el ámbito familiar se han generado cambios en los hábitos y rutinas de las personas, incluso la disolución matrimonial y familiar; 3) de la salud, algunos han enfermado de COVID-19 y/o sus familiares; 4) a nivel emocional han experimentado temor, preocupación $\mathrm{y}$ desesperación que les causa la crisis de la pandemia; 5) de los programas que el Gobierno Mexicano implementó para hacer frente a la pandemia, ninguno fue dirigido a este sector laboral semi-informal. 


\section{CONCLUSIONES}

Tanto el análisis teórico como el trabajo de campo muestran que existe un deterioro en el trabajo informal durante lo que va de la pandemia. En México, las políticas del ámbito social y de salud no han logrado dar un espacio digno y de bienestar para los sectores laborales que están al margen del marco legal, con ello exacerbando la vulnerabilidad de la población. Se vislumbra un mayor empobrecimiento de los sectores denominados informales y semi-informales.

Se puede señalar que el trabajo informal en el contexto de la pandemia por COVID-19 tiene afectaciones en el ámbito económico, en la salud física y emocional, así como en lo familiar; y en suma todo esto aumenta la precarización del trabajo. En especial los conductores de taxi no cuentan con un ingreso fijo, ni cuentan con protección social, su trabajo incrementa la exposición al COVID-19; y además no tienen derechos laborales; lo cual exacerba la vulnerabilidad laboral.

Finalmente, si las políticas públicas dirigidas al sector informal son escasas o nulas en los diferentes niveles de gobierno, y con miras a la formalización, se observa necesario que ante la crisis de la COVID-19, y posterior a ésta, se diseñen e implementen políticas orientadas a: 1) Redefinir el trabajo informal, dado que no todos los trabajadores de este sector, están plenamente fuera del marco legal; algunos pagan determinados impuestos; 2) Brindar acceso al bienestar social; si bien en México actualmente existe el esquema del Instituto de Salud para el Bienestar (INSABI), organismo de la Secretaría de Salud Federal, cuyo fin es proveer de salud a quienes carecen de la cobertura que ofrece el Instituto Mexicano del Seguro Social (IMSS), para trabajadores que no son del Estado, o el Instituto del Instituto de Seguridad y Servicios Sociales de los Trabajadores delEstado(ISSSTE), lo cierto es que no todos los trabajadores del sector informal cumplen con dicha característica, pues cubren ciertos gastos para poder laboral; 3 ) Considerar que la informalidad o semi-formalidad del trabajo guarda relación con las condiciones de pobreza y educación; 4) La incorporación a la llamada formalidad laboral, puede implicar para los trabajadores de transporte colectivo concesionado, un incremento en los gastos de tenencia, verificación, licencia de conducir, así como facilidad para obtener una concesión.

\section{REFERENCIAS}

1. Aguilar, J. (2020). México: efectos del COVID-19 en el mercado del trabajo. Instituto de investigaciones sociales de la UNAM. https://www.iis.unam.mx/blog/mexico-efectos-del-covid-19-en-el-mercadodel-trabajo/

2. Aguilar, V. L. (1992). El estudio de las políticas públicas. México: Miguel Angel Porrúa

3. Barajas, G. (2002). Las políticas de atención a la pobreza en México, 1970-2001: de populistas a neoliberales. Revista Venezolana de Gerencia, 7(20), 553-578.

4. Candelas, R. (2020). Empleo formal e informal 2020 en México. Centro de Estudios Sociales y Opinión Pública.

5. Consejo Nacional de Evaluación de la Política de Desarrollo Social (CONEVAL). (2020). Pobreza en México: resultados de pobreza en México 2020 a nivel nacional y por entidades federativas. CONEVAL. https://www.coneval.org.mx/Medicion/Paginas/PobrezaInicio.aspx

6. Consejo Nacional de Evaluación de la Política de Desarrollo Social. (2021). Panorama de los programas y acciones sociales en las entidades federativas para dar respuesta a los efectos de la pandemia por el virus SARS-CoV- 2 (COVID-19), Ciudad de México: CONEVAL.

7. Cota, R. y Navarro, A. (2016). Análisis del concepto de empleo informal en México. Análisis Económico, vol. XXXI, núm. 78, pp. 125-144, Universidad Autónoma Metropolitana. https://www. redalyc.org/jatsRepo/413/41347447007/html/index.html

8. Data México. (2020). Conductores de Autobuses, Camiones, Camionetas, Taxis y Automóviles de Pasajeros. Cuarto Trimestre de 2020. México

9. De Soto, H. (1986). El otro sendero. Paidós. España.

10. Diaz, Q. A. (2012). Estudio de la relación existente entre la informalidad y la cohesión social en la 
ciudad de México. Tesis Doctoral. Universidad Iberoamericana, México.

11. Dirección General de Prevención y Control de la Contaminación Atmosférica (DGPCCA). (2020). Exención provisional del Acuerdo Hoy No Circula. Gobierno del Estado de México. Coordinación General de Comunicación Social. https://www.gem.gob.mx/medios/w2detalle. aspx?tser $=\mathrm{C} \&$ folio $=13546 \#$

12. DOF (2020a, 30 de marzo). Acuerdo por el que se establecen acciones extraordinarias para atender la emergencia sanitaria generada por el virus SARS-CoV2. México. Secretaria de Salud. Recuperado en https://www.dof.gob.mx/nota_detalle.php?codigo $=5590914 \&$ fecha $=31 / 03 / 2020 \&$ print=true

13. DOF (2020b, 24 de marzo). Acuerdo por el que se establecen las medidas preventivas que se deberán implementar para la mitigación y control de los riesgos para la salud que implica la enfermedad por el virus SARS-CoV2 (COVID-19). Secretaria de Salud. https://www.dof.gob.mx/nota_detalle.php?codi go $=5590339 \&$ fecha $=24 / 03 / 2020$

14. DOF (2020c, 14 de mayo). Acuerdo por el que se establece una estrategia para la reapertura de las actividades sociales, educativas y económicas, así como un sistema de semáforo por regiones para evaluar semanalmente el riesgo epidemiológico relacionado con la reapertura de actividades en cada entidad federativa, así como se establecen acciones extraordinarias. México. Secretaria de Salud. https://dof.gob.mx/nota_detalle.php?codigo $=5593313 \&$ fecha $=14 / 05 / 2020$

15. DOF (2020d, 24 de junio). Programa Sectorial de Trabajo y Previsión Social 2020-2024. México. Secretaría del Trabajo y Previsión Social. https://www.dof.gob.mx/nota_detalle.php?codigo=559549 $0 \&$ fecha $=24 / 06 / 2020$

16. DOF (2021, 22 de febrero). Acuerdo mediante el cual se establecen las Reglas de Operación del Programa de Apoyo al Empleo. México. Secretaría del Trabajo y Previsión Social. http://www.dof. gob.mx/nota_detalle.php?codigo $=5611930 \&$ fecha $=22 / 02 / 2021$

17. Feix, N. (2020). México y la crisis de COVID-19 en el mundo del trabajo: respuestas y desafíos. Panorama Laboral en tiempos de la COVID-19. Organización Internacional del Trabajo.

18. Fernández, Caravaca. (2011). "La política social. Presupuestos teóricos y horizonte histórico". Aposta revista de ciencias sociales, No 50, 1-46.

19. Gobierno del Estado de México (2020a). Acuerdo de la secretaría del trabajo del estado de México, por el que se expiden las reglas de operación del programa de desarrollo social "programa de apoyo al desempleo". Gaceta del Gobierno. ventanillaelectronica.edomex.gob.mx

20. Gobierno del Estado de México (2020b). "Acuerdo del secretario de movilidad por el que se determinan las acciones a llevar a cabo por los servidores públicos de dicha dependencia, concesionarios, choferes u operadores del servicio público de transporte de pasajeros con motivo del virus sars-cov2, causante de la enfermedad covid-19" Gaceta del Gobierno. http://legislacion.edomex.gob.mx/sites/legislacion. edomex.gob.mx/files/files/pdf/gct/2020/abr223.pdf

21. INEGI (2014). La informalidad laboral: Encuesta Nacional de Ocupación y Empleo: marco conceptual y metodológico. Instituto Nacional de Estadística y Geografía, México.

22. INEGI (2021a, 17 de mayo). Resultados de la Encuesta Nacional de Ocupación y Empleo nueva edición (ENOE): cifras durante el primer trimestre de 2021. Comunicado de prensa núm. 280/21 https://www.inegi.org.mx/contenidos/saladeprensa/boletines/2021/enoe_ie/enoe_ie2021_05.pdf

23. INEGI (2021b, 19 de agosto). Resultados de la encuesta nacional de ocupación y empleo, nueva edición: cifras durante el segundo trimestre de 2021. Comunicado de prensa núm. 457/21 https://www. inegi.org.mx/contenidos/saladeprensa/boletines/2021/enoe_ie/enoe_ie2021_08.pdf

24. INEGI (2020c, 29 de abril). Estadísticas a propósito del día del trabajo: Datos nacionales. Comunicado de prensa núm.166/20. https://www.inegi.org.mx/contenidos/saladeprensa/aproposito/2020/ trabajoNal.pdf

25. INEGI, ETOE (2020, 1 de junio). Principales resultados al mes de abril de 2020. https://www.inegi. org.mx/contenidos/investigacion/etoe/doc/etoe_presentacion_resultados_abril_2020.pdf

26. Infante, R.; Martínez, D. (2019). La informalidad en la visión de la OIT: evolución y perspectivas para América Latina. Organización Internacional del Trabajo https://www.ilo.org/santiago/publicaciones/ reflexionestrabajo/WCMS_729999/lang--es/index.htm

27. Hernández, J. (2020). Impacto de la COVID-19 sobre la salud mental de las personas. Medicentro Electrónica, 24(3), 578-594. http://scielo.sld.cu/scielo.php?script=sci_arttext\&pid=S1029$30432020000300578 \& \operatorname{lng}=$ es\&tlng=es.

28. Hernández, Y.; Galindo, R. (2016). Modelo de gestión del servicio de transporte UBER. ¿Quién pierde y quién gana? Revista Espacios Públicos. Nro. 47

29. Hernández, Y.; Galindo, R. (2020). La vulnerabilidad en el trabajo de los taxistas en la Zona Metropolitana del Valle de México ante la pandemia por COVID-19. Espacio Abierto, 29 (4), 12-30. ISSN: 1315-0006. https://www.redalyc.org/articulo.oa?id=12265803001 
30. Lara, CM., De la Rosa, R. J.J. (Coords.) (2017). “Introducción”. El análisis y evaluación de políticas públicas en México: una agenda de investigación. México: Universidad Autónoma MetropolitanaUnidad Lerma

31. Ledesma, D., Poó, M., Úngaro, J., López, S, Cirese, P., Enev, A., Nucciarone, I., \& Tosi, D. (2017). Trabajo y Salud en Conductores de Taxis. Ciencia \& trabajo, 19(59), 113-119. https://dx.doi. org/10.4067/S0718-24492017000200113

32. Levi, S. (2010). Buenas intenciones, malos resultados: política social, informalidad y crecimiento, México: Oceano Editorial.

33. Cámara de Diputados del H. Congreso de la Unión. (2021, 31 de julio). Ley Federal del Trabajo. Diario Oficial de la Federación. http://www.diputados.gob.mx/LeyesBiblio/pdf/125_310721.pdf

34. Martínez, M. A., Morales, G. MA. (2021). "Adecuaciones de políticas sociales transexenales para armonizar con la 4T: el caso del programa de coinversión social”, en Sosa, J. M; Hernández, M. R., Dávila, J. M. (Coords.). Las políticas y los programas públicos en el marco del gobierno de la 4T en México ¿Continuidad o Transformación?. Universidad Autónoma Metropolitana-Lerma, México.

35. Martínez, O. G. (2021). Empleo informal y crisis por la covid-19: la implementación de políticas dirigidas al sector informal, el caso de los taxistas de xonacatlán- puente san mateo. Tesis de licenciatura. Universidad Autónoma Metropolitana Unidad Lerma.

36. Midgley, J. (2009). “The definition of social policy “, en Midgley, James y Michelle Livermore (edits.) The handbook of social policy, Los Angeles: Sage, pp. 3-20.

37. OCDE (2020). Sesión 1 "La informalidad y la protección del empleo durante y después de COVID-19: buenas prácticas y la necesidad de redes de seguridad universales" Cumbre Ministerial Virtual sobre Inclusión Social para América Latina y el Caribe.

38. OIT (2003). Directrices sobre una definición estadística de empleo informal, adoptadas por la Decimoséptima Conferencia Internacional de Estadísticos del Trabajo, Ginebra.

39. OIT (2013). La economía informal y el trabajo decente: una guía de recursos sobre políticas, apoyando la transición hacia la formalidad / Oficina Internacional del Trabajo, Departamento de Política de Empleo. - Ginebra.

40. OIT (2014). Panorama Laboral Temático: Transición a la formalidad en América Latina y el Caribe. Lima: OIT, Oficina Regional para América Latina y el Caribe, $80 \mathrm{p}$.

41. OIT (2018). Definición y medición estadísticas del trabajo "por cuenta propia" económicamente dependiente. $20^{\mathrm{a}}$ Conferencia Internacional de Estadísticos del Trabajo. Documento de sala número 6, Ginebra.

42. Ovando, W. y Salgado, M. (2021). Empleo informal en México durante la pandemia de COVID-19. Economía Actual Año 14, Núm. 2. Universidad Autónoma del Estado de México.

43. Pérez, J. (2021). Situación laboral de la población económicamente activa de 18 años y más por el efecto de la pandemia. Respuestas del mercado, del gobierno y de la familia.

44. Pogliaghi, L. (2012). Entre el control y la libertad: configuraciones de trabajo, identidad y acción colectiva de los taxistas de la ciudad de México. Tesis Doctoral. Universidad Autónoma Metropolitana Unidad Iztapalapa.

45. PREALC/OIT (1976). El problema del empleo en América Latina: Situación, perspectivas y políticas. Santiago de Chile.

46. Rivera, R; López, N.; Mendoza, A. (2015). Políticas de apoyo a la productividad de la microempresa informal ¿dónde está México? Revista Problemas del Desarrollo 184 (47).

47. Robles, D. (2016). La evasión fiscal en la economía informal: consideraciones para una reforma fiscal en México. IPN, México, Ciudad de México.

48. Secretaría de Economía (2020). Créditos a la palabra para reactivar la economía $\mid 2$ de junio de 2020 \#UnidosSaldremosAdelante. [Video] Gobierno de México.

49. Secretaría de Gobernación (2019). En 2019, 23\% del PIB fue informal y se generó por el $56.5 \%$ de la población ocupada. México. Gaceta Económica. Recuperado en Gob.mx. https://www.gob.mx/ shcp/gacetaeconomica/articulos/en-2019-23-del-pib-fue-informal-y-se-genero-por-el-56-5-de-lapoblacion-ocupada

50. Secretaría de Gobernación, CONACYT (2021). Covid-19 México: información General. Gobierno de México Recuperado de https://datos.covid-19.conacyt.mx/

51. Secretaría de Movilidad del Estado de México (2021). Trámites y Servicios. https://retys.edomex.gob. $\mathrm{mx} /$ catego/T13/Transporte\%20y\%20Urbanismo/1?

52. Secretaría de Salud [@SSalud_mx]. (18 de marzo de 2020). Hoy en México falleció la primera persona con \#COVID19. [Tweet]. Twitter. https://twitter.com/SSalud_mx/status/1240499937433006081?s=20

53. Tokman, V. (1987). El sector informal: quince años después. El Trimestre Económico, 54, 215 (3), págs. 513-536. 